\title{
Design and Optimization of Fins in Solar Flat Plate Collector Using CFD
}

\author{
Mohammed Abdul Junaid ${ }^{1}$, S. Irfan Sadaq ${ }^{2}$ \\ ${ }^{1}$ Assistant Professor, Lords Institute of Engineering \& Technology, Department of Mechanical Engineering, \\ Sy No.32, Himayathsagar, Hyderabad, T.S, India, 500091 \\ ${ }^{2}$ Assistant Professor, Department of Mechanical Engineering, M.J.C.E.T, Osmania University, \\ Road No.3, Banjara Hills, Hyderabad, T.S, India, 500034
}

\begin{abstract}
The main objective of this paper is to present design of solar flat plate collector with internal fins i.e., 2, 3, 4 and without fins using CAD software to perform thermal analysis in the month of March at 11am, 12, 1pm \& 2pm keeping the mass flow rate as constant to optimize the internal fins. For modeling purpose GAMBIT 2.4 is used \& for analysis ANSYS FLUENT 14.5 is used.
\end{abstract}

Keywords: Modeling, Thermal Analysis, Internal Fins

\section{Introduction}

Solar energy is the most considerable energy source in the world. Sun, which is $1.495 \times 10^{11}(\mathrm{~m})$ far from the earth and has a diameter of $1.39 \times 10^{9}(\mathrm{~m})$, would emit approximately $1353\left(\mathrm{w} / \mathrm{m}^{2}\right)$ on to a surface perpendicular to rays. The world receives 170 trillion (kw) solar energy and $30 \%$ of this energy is reflected back to space, $47 \%$ is transferred to low temperature heat energy, $23 \%$ is used for evaporation/rainfall cycle in the Biosphere and less than $0.5 \%$ is used in the kinetic energy of the wind, waves and photosynthesis of plants.

Solar energy collection systems are of various types. The most important collection system is solar collector where the heat transfer from the sun to an absorber and absorber to fluid occurs. In order to affect the performance of this system, generally modifications on solar collectors are performed [1]

\section{Flat Plate Collector}

Flat plate collectors are most common for residential waterheating and space-heating installations. A flat plate collector consists of an absorber, glazing covers and an insulated box as shown in fig 1 . The absorber is sheet of high thermal conductivity metal sheet with tubes integral attached. The insulated box provides structure and sealing and reduces heat loss from the back and sides of the collector [2]. The cover sheets, called glazing, allow sunlight to pass through to the absorber but insulate the space above to prevent cool air from flowing into this space. The glass reflects a small part of the sunlight, which does not reach the absorber.

The absorber plate which covers the full aperture area of the collector performs three functions: absorb the maximum possible amount of solar irradiance, transfer this heat into working fluid at a minimum temperature difference and lose a minimum amount of heat back to the surroundings.

Solar irradiance passing through the glazing is absorbed directly onto the absorber plate. As the second function of the absorber plate is to transfer the absorbed energy into a heattransfer fluid at a minimum temperature difference, is achieved by conducting the absorbed heat to tubes that contains the heat transfer fluid.

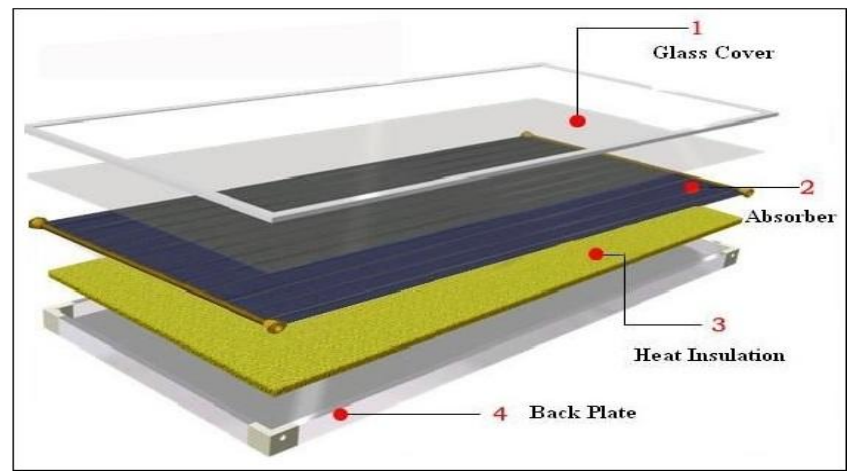

Figure 1: Flat plate solar water Collector.

Transferring the heat absorbed on the absorber surface into the water give rise to heat losses. Liquid collector absorber plates consist of a flat sheet with tubes spaced $10 \mathrm{~cm}$ apart and attached to it. The tubes are not spaced too apart otherwise a much lower temperature will occur halfway between them.

\section{Heat Transfer}

Heat Transfer is the thermal energy exchange between bodies when there is a temperature differences them. Thermal energy is transferred from the higher temperature, to the lower temperature. Temperature is a measure of the amount of energy molecules a body holds. In SI units, heat is typically denoted by the symbol Q and it is expressed in joules $(\mathrm{J})$. The rate of heat transfer $\mathrm{q}$ is measured in watts (W), which are joules per second. The rate of heat transfer per unit area, heat flux, is measured in watts per area $\left(\mathrm{W} / \mathrm{m}^{2}\right)$.

Heat transfer processes are classifies into three modes: conduction, convection $\&$ radiation. Conduction occurs when there is a temperature gradient across a body. It is an energy transfer across a system due to random molecular movement. 


\section{International Journal of Science and Research (IJSR) \\ ISSN (Online): 2319-7064 \\ Index Copernicus Value (2017): 78.96 Impact Factor (2017): 6.391}

Higher temperature is related with higher molecular energies, hence when they collide with molecules of lower energy and conduction occurs.

The second heat transfer process is convection where the motion of fluids (gas or liquids) is used to transfer heat. The convection heat transfer can be natural (free) convection where the fluid motion is created by the warm fluid itself. The density of fluid decreases as it is heated and it becomes lighter than the cold fluid. Forced convection occurs when the flow is caused by external means, such as pumps. The third process is radiation where the transmission of energy is achieved without the presence of a body. Radiation travels at the speed of light and it is emitted by any matter with temperature above $0 \mathrm{~K}$. This mode of heat transfer takes place when the emitted radiation strikes another body and it is absorbed [3].

\section{Internal Fins Concept Selection}

In recent years solar energy has been strongly promoted as a viable energy source. One of the simplest and most direct applications of this energy is the conversion of solar radiation into heat. Hence way that domestic sector can lessen its impact on the environment is by installation of solar flat plate collectors for heating water. Although it should be said that some of these collectors have been in service for last 40-50 years without any real significant changes in their design and operational principles.

So, research work done and presented in this paper is concerned with improvement of the efficiency of solar flat plate collector using internal fins in the channels of the collector to increase the heat transfer. This is examined by the design of collector model utilizing computational Fluid Dynamics (CFD) ANSYS Fluent package.

\subsection{Design Consideration}

The proposed CFD design employs a geometry consisting of two vertical cylindrical pipes and 19 horizontal pipes. Inside these horizontal and vertical pipes, fins are incorporated.

The software work involves simulation conducted on the design equipped with two glazed solar collector. The first type used is without incorporation of fins design, whilst the second one is incorporated with fins $2,3 \& 4$ in all pipes.

The basic parts of the full-aperture are absorber plate, two transparent covers sheets and insulation. Including to these parts, air gap between the top glass cover and bottom glass cover and air gap between bottom glass cover and absorber plate are also considered as volumes. Specifications of all parts of Collector are shown in table 1.

Table 1: Specifications

\begin{tabular}{|l|c|l|l|}
\hline Description & \multicolumn{2}{|c|}{ Specification } & Material \\
\hline Area of Glazing Cover & 10193.5 sq.cm & Glass \\
\hline Area of Absorber Plate & \multicolumn{2}{|c|}{10193.5 sq.cm } & Copper \\
\hline Diameter of Tube & \multicolumn{2}{|c|}{$1.6 \mathrm{~cm}$} & Copper \\
\hline Insulation Thickness & \multicolumn{2}{|c|}{$4 \mathrm{~cm}$} & Wool \\
\hline \multirow{2}{*}{ Fin } & Width & $0.8 \mathrm{~cm}$ & Copper \\
\cline { 2 - 4 } & Thickness & $0.1 \mathrm{~cm}$ & \\
\hline
\end{tabular}

Volume 6 Issue 1, January 2017
The absorber sheet is of high thermal conductivity metal with tubes attached. To minimize radiant emission, the cover sheet called glazing is used. Outer faces of the water volumes are considered as pipes while doing the simulation using shell condition process.

\subsection{Modeling}

The full geometry of collector were created in the Gambit Software using the various features available in gambit to create various parts of collector with the help of specifications given in table 1 to get the model of the collector which is shown in fig 2, Computational mesh is used as a pre-processor for the CFD solver and post processor, namely FLUENT in gambit.

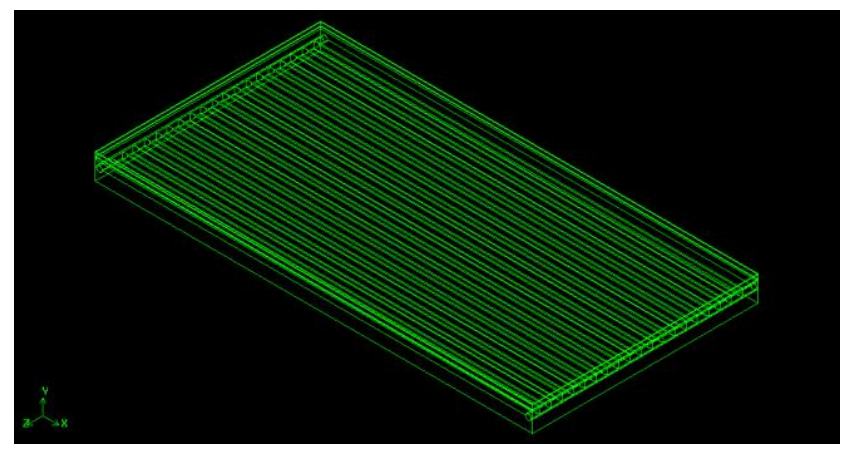

Figure 2: Collector without Fins

\subsection{Meshing}

A time consuming process while designing the proposed geometry was the creation and later meshing of the volume of the water within the pipe. The difficulty occurred because of the complex shape of this particular volume of water. This was due to the large number of pipes created at the external surface of the water because of parallel connection as shown is shown in fig 3 . That shape is then projected at the volume water. The computer package had difficulties in dealing with this profile.

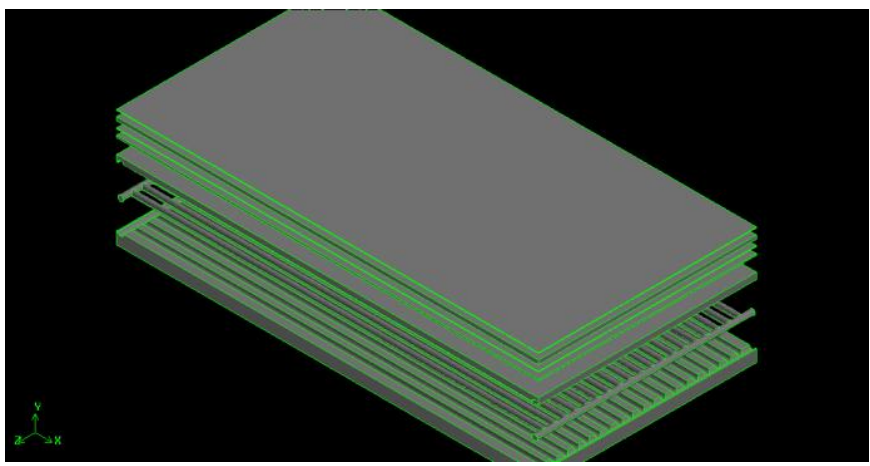

Figure 3: Exploded View of Collector

The meshing element-scheme used for meshing the whole domain was Tetrahedral/Hybrid. This scheme allowed the mesh to be composed primarily of tetrahedral mesh elements including wedge (prism) elements where appropriate. The total number of mesh cells created in the entire geometry was about 72.60 lacks with density of the grid being grater in some areas as shown in fig 4. 


\section{International Journal of Science and Research (IJSR) ISSN (Online): 2319-7064}

Index Copernicus Value (2017): 78.96 | Impact Factor (2017): 6.391

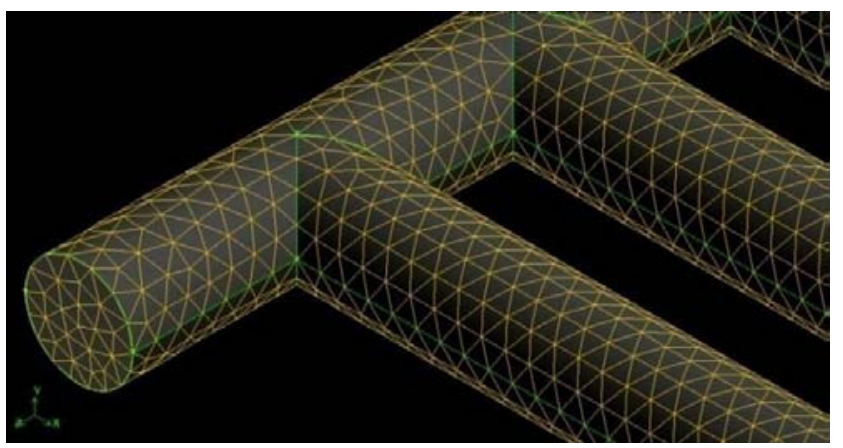

Figure 4: Meshed Pipe without Fins

In the pre-processor program i.e., GAMBIT volumes are specified for meshing operation, shape and topological characteristics and type of mesh are also determined. Meshing Scheme is specified by two parameters i.e., elements and type. The elements parameters define the shape of the elements that are used to mesh the volume while type parameter defines the meshing pattern of mesh elements in the volume.

\subsection{Location of Simulation}

The location for performing simulation is chosen as Muffakham Jah college of Engineering and Technology, Mechanical Branch as shown in fig 4. The Coordinate for the location is $17^{\circ} 39 \mathrm{~N}$; E $78^{\circ} 4323.378 \mathrm{E}$. The location is suitable to run the simulation because the area receives sufficient amount of sun radiation.

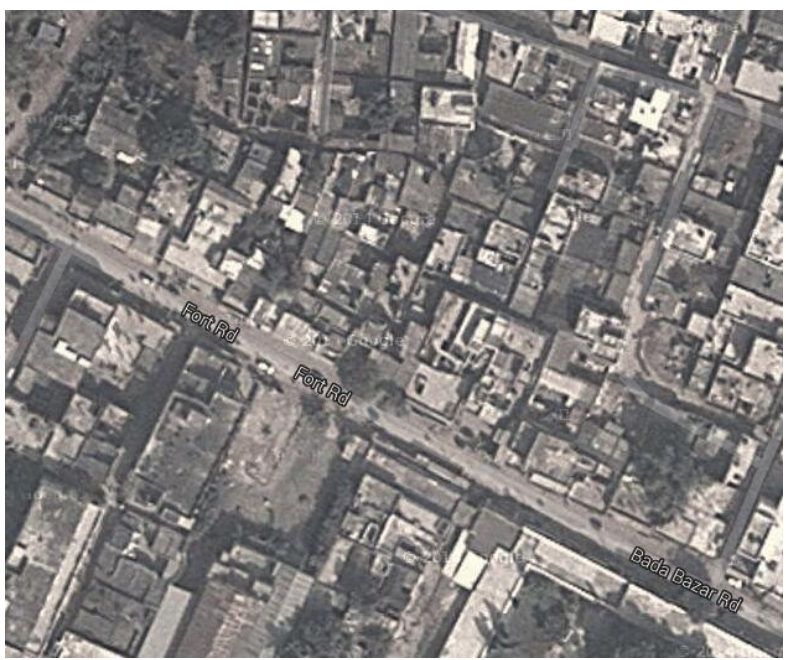

Figure 4: Satellite Image of the Location [4]

\section{Analysis}

\subsection{Analysis of Un-Finned Collectors}

First four cases are investigated in the month of March considered average weather conditions at $11 \mathrm{am}, 12,1 \mathrm{pm} \&$ $2 \mathrm{pm}$ with un-finned pipes.

After giving all the necessary inputs i.e. properties of various volumes of collector to the software as shown in table 2 it performed the calculations inside it and gives the related output in the form of counters for distribution of parameters, reports which includes data at various faces and graphs.
Table 2: Properties

\begin{tabular}{|c|c|c|c|}
\hline Description & $\begin{array}{c}\text { Density } \\
\left(\mathrm{Kg} / \mathrm{m}^{3}\right)\end{array}$ & $\begin{array}{c}C_{p} \\
(\mathrm{~J} / \mathrm{kgK})\end{array}$ & $\begin{array}{c}\text { Thermal } \\
\text { Conductivity }(\mathrm{W} / \mathrm{m}-\mathrm{k})\end{array}$ \\
\hline Glass & 2400 & 670 & 0.96 \\
\hline Copper & 8978 & 381 & 387.6 \\
\hline Insulation Wool & 48 & 670 & 0.05 \\
\hline Air & 1.225 & 1006.43 & 0.0242 \\
\hline Water & 998.2 & 4182 & 0.6 \\
\hline
\end{tabular}

After performing simulation on the above four cases, weather conditions at 12.00 shows good results. Temperature in glazing covers, air gaps, absorber plate, insulation and outlet of flat plate collector is more at 12.00. Solution of the solar flat plate collector without fins is converged at 815 iterations.

Overall temperature distribution in complete Collector without fins at 12.00 in the month of March is shown in fig 5.

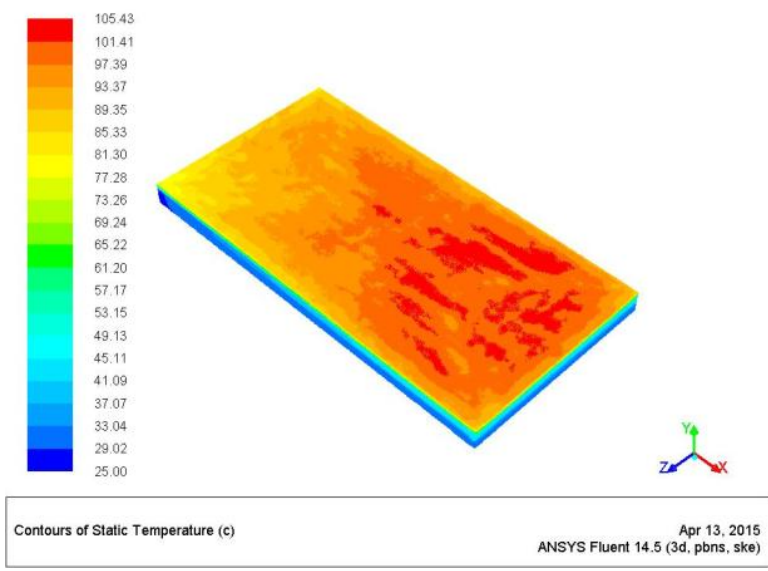

Figure 5: Temperature distribution in collector at 12.00

Temperature distribution in pipe is progrssively increases from inlet of the pipe to outlet in cross manner as shown in fig 6

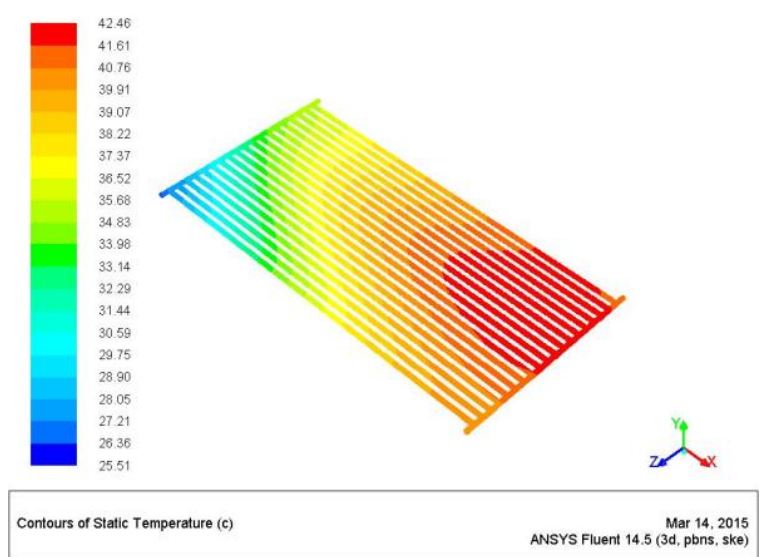

Figure 6: Temperature Distribution in Pipe at 12.00

\subsection{Analysis of finned collectors}

\subsubsection{Modeling of Fins in Collector}

After performing simulation on four cases we come to know that 12.00 case results shows maximum heat transfer, output temperature of water and efficiency are also maximum. So weather conditions at this case are selected and replaced these un-finned pipes with finned pipes $(2,3,4)$ in order to

\section{Volume 6 Issue 1, January 2017




\section{International Journal of Science and Research (IJSR) \\ ISSN (Online): 2319-7064}

Index Copernicus Value (2017): 78.96 Impact Factor (2017): 6.391

check whether the output temperature of water and efficiency increase or decreases.

\subsubsection{Designing of Fins in Collector}

The following points are considered and adapted in designing fins inside the pipes of collector.

1)The fin is made of a material with high thermal conductivity.

2) The fin is thin to maximize the temperature required to transfer heat to tube.

3)Tubs are not spaced too far, to avoid a temperature difference.

4) Tubes and fins are made of similar material to prevent galvanic corrosion between them.

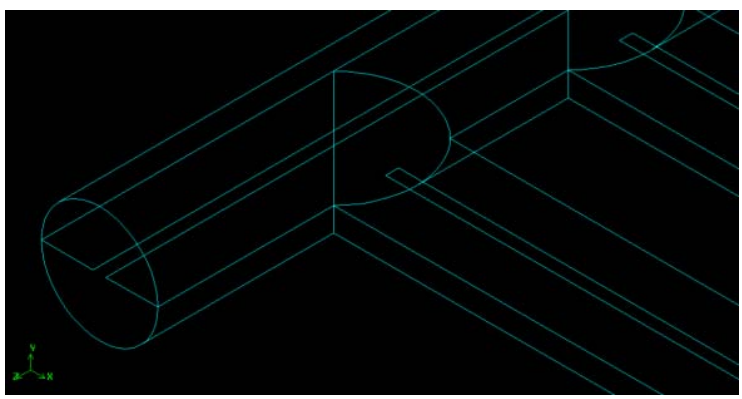

Figure 7: 2finned pipes

Geometry of the 2 finned pipes for computational purpose is combination of circular pipes and fins arranged circularly or equally spaced rectangular fins of the same lengths as shown in fig 7. Similarly 3 finned pipes and 4 finned pipes are created using features in gambit as shown in fig 8 and fig 9 respectively.

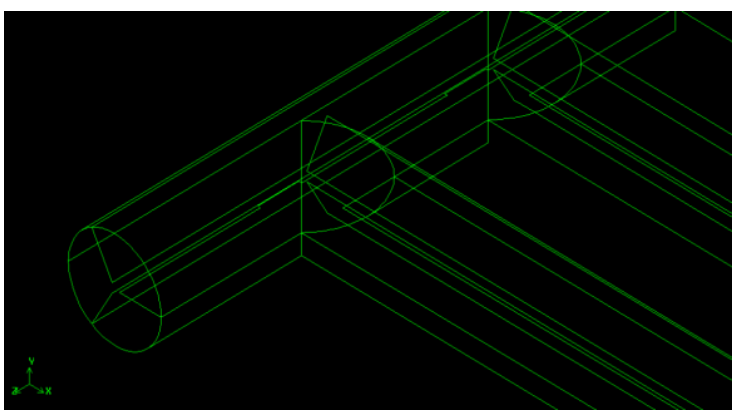

Figure 8: 3 Finned Pipes

Outer faces of the pipes and fins designed inside are considered as shell conduction in CFD simulation. So these faces are considered as fins walls while specifying the boundary entities.

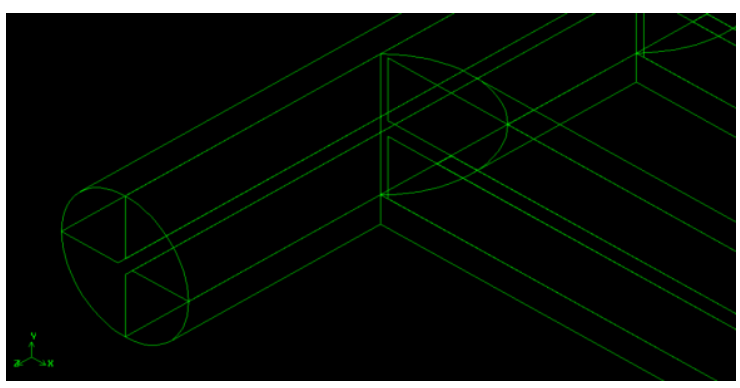

Figure 9: 4 Finned Pipes

\subsubsection{Analysis of Finned Collectors}

Output temperature of the water is increases in collector with 2 fins and decreases in 3 fins and again decreases in 4 fins as shown in fig 10 , fig $11 \&$ fig 12 respectively.

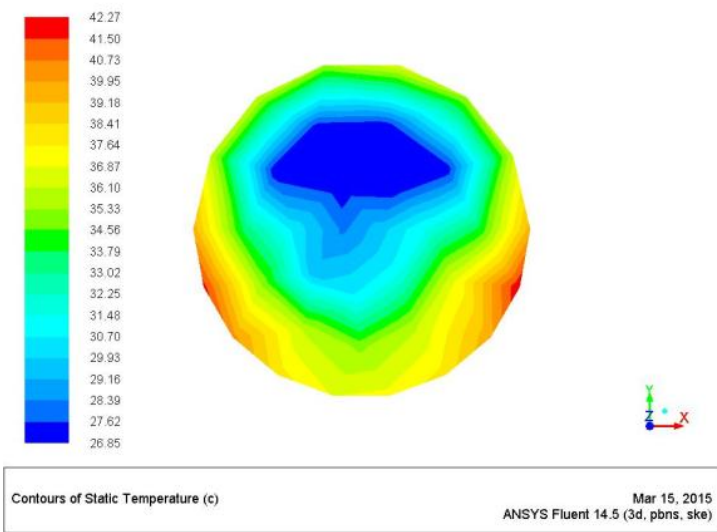

Figure 10: Output Temperature of Water with 2 fins

After performing the simulation work of all cases then efficiencies are calculated by taking the flux reports from the software.

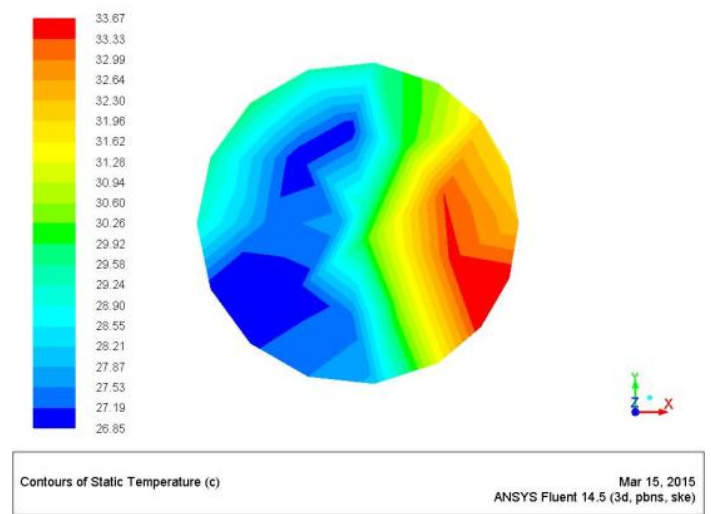

Figure 11: Output Temperature of Water with 3 fins

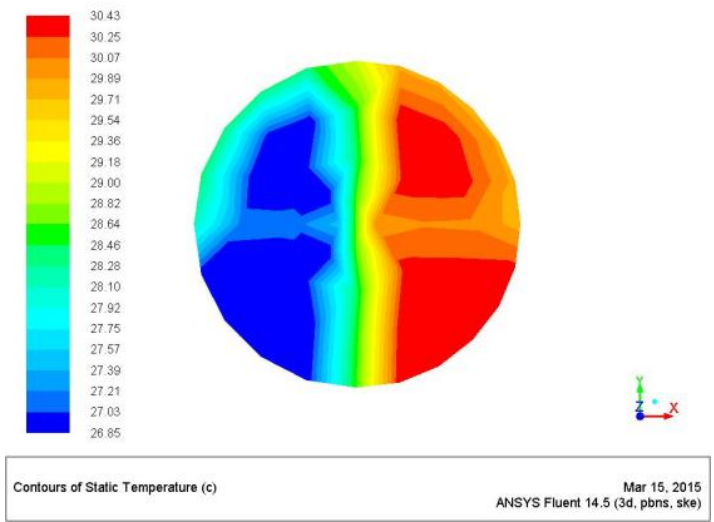

Figure 12: Output Temperature of Water with 4 fins

\section{Conclusion}

From the simulation of FPC without fin at 11.00am to FPC with 4 fins at 12.00 with respect to time is calculated. The output temperature is more in 2 finned collector i.e., $42.27^{\circ} \mathrm{C}$ when the inlet temperature of water is $25^{\circ} \mathrm{C}$ so there is an increase in $18^{\circ} \mathrm{C}$ and as the number of fins increases output temperature is decreases as shown in graph 1. 


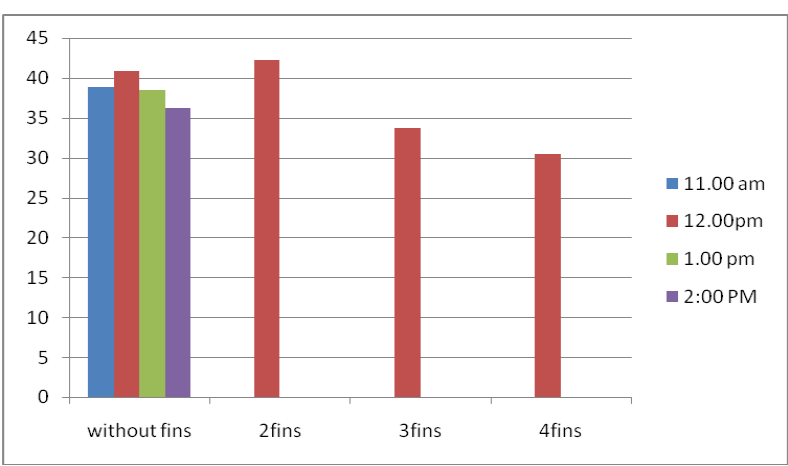

Graph 1: Output Temperature Variations

Similarly the efficiency is also more in case of 2 finned collector i.e., $98 \%$ and gradually decreases as the number of fins increases as shown in graph 2

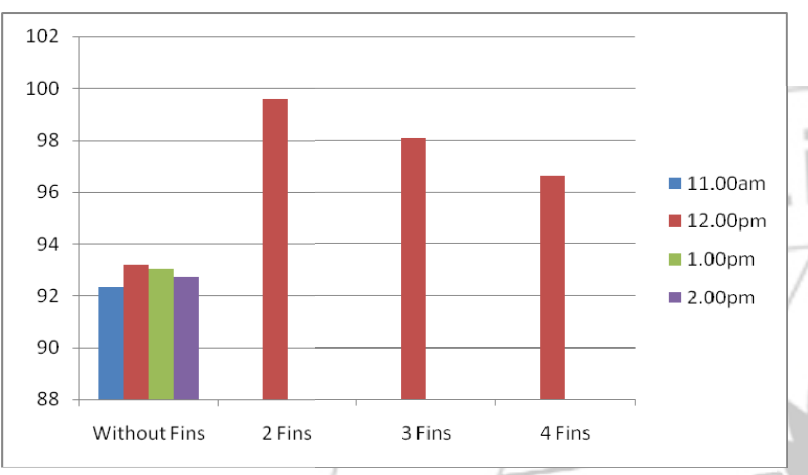

Graph 2: Efficiency Variations

From these graphs output temperature and Efficiency were maximum in Solar Flat plate collector at 12.00 with 2 fins.

\section{References}

[1] International Journal of Emerging Technology and Advanced Engineering Website: www.ijetae.com (ISSN 2250-2459, ISO 9001:2008 Certified Journal, Volume 3, Issue 4, April 2013).

[2] U.S. Department of Energy - Energy Efficiency and Renewable Energy Solar Energy Technologies Program. http://wwwl.eere.energy.gov/solar

[3] "Handbook of Heat Transfer" by Warren M.Rohsenow, James P. Hartnett, Young I. Cho, MCGRAW-HILL, 3rd Edition, ISBN 0-07-053555-8.

[4] Satellite Image of Location,www.google.com/map 